\title{
Technology solutions for sustainable urban community design in subtropical Taiwan
}

\author{
S. F. $\operatorname{Lin}^{1} \&$ N. T. Chao ${ }^{2}$ \\ ${ }^{1}$ Department of Architecture, Shih Chien University, Taipei, Taiwan \\ ${ }^{2}$ Creativity Lab, ITRI, Hsin-Chu, Taiwan
}

\begin{abstract}
Subtropical Taiwan has to import $99 \%$ of the required energy. With limited usable land and intensified urban development, the living quality is less than desirable due to air pollution, over heating, and lack of green outdoor spaces. Aiming at sustainable urban development, the Taiwan government recognizes that appropriate technologies have to be identified and developed to better cope with the challenges. It is found that the community is an appropriate context in which to explore sustainable development issues. The criteria to approach the issues are self-sufficiency, short-distance, and sharing to deal with energy/resources conservation, a healthy environment, and the aging population. For self-sufficiency, the core concept is to consume less commercial energy and recycle/reuse waste and water. For short distances, the main idea is to reduce the transportation frequency of people/goods and to promote zero-emission mobility. For sharing, the goal is to promote virtual and physical interpersonal interaction.
\end{abstract}

Keywords: subtropical, sustainable, urban, community, technology, energy saving, renewable energy, waste, water, transportation.

\section{Introduction}

Taiwan is situated in a subtropical region, whereby the climate is warm and humid. The annual average climatic data are: temperature $23^{\circ} \mathrm{C}$, relative humidity $80 \%$, rainfall $2,510 \mathrm{~mm}$, solar irradiance $942-1,584 \mathrm{kWh} / \mathrm{m}^{2} \mathrm{yr}$.

Due to a shortage of indigenous energy, Taiwan has to import $99 \%$ of the required energy [1]. It is estimated that wind power may provide 3,000 MW and 
geothermal 1,000 MW per year [2]. The renewable energy (solar thermal, photovoltaic, and wind power) accounted for $0.1 \%$ of the total energy supply in 2007. For the past 20 years, the electricity consumption of the residential and service sectors has grown steadily from $27.89 \%$ to $37.03 \%$ and the electricity consumption per capita has trebled [1].

The liveable land accounts for only $6 \%$ of the homeland. The average greenery coverage is $15 \%$ in urban areas. There are $73 \%$ of the population residing in urban areas and the density reaches 3,929 person $/ \mathrm{km}^{2}$, ranking $61^{\text {st }}$ in the world [3]. The total population is 22.9 million in which elderly people account for $10.2 \%$.

The community empowerment in Taiwan has been developed for 20 years [3]. The primary goal is to improve living quality with volunteer forces, in the three aspects of environment, economy, and society. At an early stage, a more top-down approach to the hardware construction of buildings/parks and environmental reform was taken. Currently, health issues related to the physical body, the environment, and inter-personal relationships have received tremendous attention along with an aging population.

\section{Analysis}

The Taiwan government has been concerned about the improvement of urban environmental quality by sustainable approaches. It is recognized that appropriate technologies have to be identified and developed to better cope with the challenges.

\subsection{Energy and resources}

From previous studies [4] it was observed that the energy consumption level of subtropical buildings is lower than that in regions with hot summers/cold winters and chilled winters. It is found that the average Taiwanese household consumes $25 \%$ of its electricity for summer cooling and over $90 \%$ of the cooling load is from outdoors [5]. For commercial buildings, 47\% of the electricity goes for lighting and $30 \%$ for cooling. Therefore, the two key issues for an effective energy saving in subtropical buildings are to improve the insulation level and to enhance daylight design.

Taiwan has a high humidity level and the solar-resource is less than bountiful due to lower irradiance (less than 2,000 $\mathrm{kWh} / \mathrm{m}^{2} \mathrm{yr}$ ) and less sun hours (around 3 hours). In addition, the building density is high and the corresponding shade off effect is strong in urban areas. The cost-effective way of applying photovoltaic electricity to urban housing needs to be further explored and examined.

Taiwan frequently experiences water shortages due to high runoff caused by steep-sloped geography, although there is a bountiful rainfall, greater than 2,000 $\mathrm{mm} / \mathrm{yr}$. It is necessary to include rainwater harvesting and water saving in urban housing design. 


\subsection{Environment}

All major Taiwanese cities experience heat island effects. Compared to highlatitude countries, the strength of the heat island effect in Taiwan is lower and the urban/suburban temperature difference is around $2 \sim 5^{\circ} \mathrm{C} \mathrm{[6].} \mathrm{The} \mathrm{current}$ greenery coverage in the major cities of Taiwan is $15 \%$, and this figure is expected to rise to $30 \%$. It is found that the urban air temperature may reduce by $0.13 \sim 0.28^{\circ} \mathrm{C}$ with every $10 \%$ increment in greenery coverage. Aside from planting more trees, it will be effective to make use of each flat roof and turn it green.

Transportation accounts for $20 \%$ of the total $\mathrm{CO} 2$ emission [7]. In the past 10 years, the number of cars and motorbikes has grown steadily in Taiwan. It is estimated that there is one car for every four persons and one motorbike for every two persons. The high vehicle emission level deteriorates urban air quality and the high air-borne particle level consequently intensifies the heat island effect. To effectively reduce traffic emissions, it is necessary to promote cycling, walking, and zero-emission vehicles.

\subsection{Society}

Health promotion has gradually begun to concern community empowerment organizations in Taiwan, along with the aging society. There are four determinants of health, which are personal health practices, biological endowment, environmental risk factors, and health service accessibility [8]. It is found that longevity is greatly influenced by personal health practices and environmental risk factors. The environmental risk can be reduced by government endeavours to reform environment, while personal health practices depend on individual awareness and determination. It is expected that the governmental medical care expanse will be greatly reduced if the knowledge and capability of self-care can be provided and improved. The outcome is twofold to alleviate the taxpayer burden and to improve public health and living quality.

\section{Strategy}

It is found that the community is an appropriate context in which to explore sustainable development issues. The criteria to approach the issues are selfsufficiency, short-distance, and sharing to deal with energy/resources conservation, the healthy environment, and the aging population.

\subsection{Self-sufficiency}

The core concept is to consume less commercial energy in buildings and recycle/reuse waste and water. For the subtropical urban community, the key issues are summarized as follows.

- Energy saving: to better insulate building enclosures.

- Renewable energy: to apply photovoltaic electricity to shared utilities. 
- Water: to develop a vertical rainwater harvesting system to be better integrated with apartments.

- Waste: to develop concentrated systems for kitchen/toilet waste composting and water recycling for each apartment building.

\subsection{Short-distance}

The main idea is to reduce the transportation frequency of people/goods and to promote zero-emission mobility. For the subtropical urban community, the approaches are summarized as follows.

- Permaculture: to promote local agriculture and make use of community produced compost and rainwater to provide food and increase green coverage to reduce the urban heat island effect.

- Zero-emission mobility: to promote walking, cycling, and zero-emission vehicles within a community and for inter-community transportation.

- Virtual working environment: to encourage different working patterns and working places with the help of information and communication technologies.

\subsection{Sharing}

The goal is to promote virtual and physical interpersonal interaction. For the subtropical urban community, the methods are summarized as follows.

- Information centre: to extend the function of the community convenience store to local information centre to provide and exchange local news.

- Meeting place: to create more indoor and outdoor places for people to meet and talk.

- Exercise within the neighbourhood: to turn apartment staircases and public spots into workout places.

\section{Conclusion}

Subtropical Taiwan has to import $99 \%$ of the required energy. With limited usable land and intensified urban development, the living quality is less than desirable due to air pollution, over heating, and the lack of green outdoor spaces. Aiming at sustainable urban development, the Taiwanese government recognizes that appropriate technologies need to be identified and developed in order to better cope with the challenges.

It is found that the community is an appropriate context in which to explore sustainable development issues. The criteria to approach the issues are selfsufficiency, short-distances, and sharing to deal with energy/resources conservation, the healthy environment, and the aging population.

For self-sufficiency, the core concept is to consume less commercial energy and recycle/reuse waste and water. The approaches are to better insulate building enclosures, to apply photovoltaic electricity to shared utilities, and to develop concentrated systems for kitchen/toilet waste composting and water recycling for each apartment building. For short-distances, the main idea is to 
reduce the transportation frequency of people/goods and to promote zeroemission mobility. The methods are to promote permaculture on rooftops for food and greening, to promote zero-emission mobility within a community and for inter-community transportation, to create virtual working environments to accommodate various working patterns and places with the help of information and communication technologies. For sharing, the goal is to promote virtual and physical interpersonal interaction. The methods are to combine local information centre with the community convenience store, to provide more meeting places, and to make use of public spots and staircases for working out.

\section{References}

[1] Bureau of Energy (BOE). Energy Statistical Handbook 2007, Taipei, Taiwan.

[2] Environmental Protection Administration Executive Yuan, http://e-info.org. $\mathrm{tw} /$ issue/energy/2001/sub-energy01020601.htm

[3] Department of Statistics/Ministry of Interior, http://www.moi.gov.tw/stat/

[4] Yoshino, H., Z. Jiang, Z. Li, N. Li, J. Liu, W. Lu, Q. Pei, J. Zheng, and Y. Zhu. Investigation of Urban Residential Energy Consumption in China, Proceedings of The First International Conference on Building Energy and Environment, Dailian, China, pp. 284-291, 2007.

[5] Wang, P.C., C.C. Chen, Y.I. Hsu, T.L. Wang, and N.T. Chao. Properties required for subtropical residential enclosure to achieve energy conservation. Proceedings of SB04 Conference, Shanghai, China, pp. 206212, 2004.

[6] Kuo, SC. Concept of urban heat island effect. http://siraya.riceball.net/ research/uc/heatisl/heatisl.htm

[7] Chang, DP. How shall Taiwan face global warming? http://www.peopo.org/ portal.php?op=viewPost\&articleId $=18343$

[8] WHO, 1999. Health 21- Health for All in the 21st Century. Copenhagen: WHO Regional Office for Europe. 